\title{
¡Todo me gustó! Los niños y sus percepciones de una actividad educativa en un museo
}

\section{I like it all! Children and their perceptions of an educational activity in a museum}

\author{
María Fernanda Melgar ${ }^{1}$ \\ fernandamelgar@gmail.com \\ Universidad Nacional de Río Cuarto, Argentina \\ Consejo Nacional de Invetsigaciones Científica y Técnicas
}

\section{Resumen:}

En este trabajo interesan los niños como público específico de los museos. En el artículo se presenta un estudio realizado en Argentina que tiene por objetivo conocer y analizar las percepciones y experiencias de niños en museos. Participaron 133 niños y niñas ubicados en la franja etaria de los 8 a los 13 años de escuelas de gestión pública y privada, rurales y urbanas. Para la recolección de datos se empleó un cuestionario con ítems que requerían respuestas abiertas y cerradas. Para el análisis de los datos se utilizó un enfoque mixto. Los resultados se presentan en tres categorías: percepciones sobre los museos, experiencias previas y valoraciones de una actividad particular. En general los niños valoraron positivamente sus experiencias en el museo, se observó un alto grado de satisfacción principalmente en sus afirmaciones referidas a aquellos aspectos que les gustaron. Los resultados del trabajo plantean numerosos desafíos para los museos y las escuelas en relación a la posibilidad de diseñar propuestas educativas contextualizadas a las características de los niños.

\begin{abstract}
:
In this paper we look at children as a specific public of museums. We present a study undertaken in Argentina. The aim of the research was to know and analyse the perceptions and experiences of children in museums. The study surveyed 133 children from different backgrounds (state and private schools and rural and urban settings) aged 8-13. For data collection, a questionnaire was used with open and closed response items. A mixed approach was used. The outcomes are presented in three categories: perceptions about museums, previous experiences and assessments of a particular activity. The children valued positively their experiences in the museum, a high degree of satisfaction was observed mainly in their affirmations referring to those aspects that they liked. The outcomes of the study raise many challenges for museums and schools in relation to the possibility of designing educational proposals which align with the characteristics of children.
\end{abstract}

1 Dirección para correspondencia (correspondence address):

María Fernanda Melgar. Departamento de Ciencias de la Educación. Universidad Nacional de Río Cuarto. Arrayanes 2537 CP (580) (Argentina). 
¡Todo me gustó! Los niños y sus percepciones de una actividad educativa en un museo

Palabras clave:

Museos; niños; escuela; estudio de público.

\section{Key words:}

Museum; children; school; public study.

\section{Résumé:}

Dans ce travail, l'étude des enfants comme public spécifique des musées nous intéresse. Dans cet article nous présentons une étude réalisée en l'Argentine. Le but de cette recherche a été de connaître et d'analyser les perceptions et expériences des enfants dans un musée. 133 enfants -garçons et filles ayant entre 8 et 13 ans-, appartenant à des écoles publiques et privées, rurales et urbaines ont participé au projet. Pour l'obtention des données nous avons employé un questionnaire avec des items qui proposaient des réponses ouvertes et fermées. Pour l'analyse des données nous avons choisi une approche mixte. Les résultats se présentent sous trois catégories : perceptions sur les musées, expériences préalables et valorisations d'une activité particulière. En général les enfants ont valorisé positivement leurs expériences dans le musée ; nous avons observé un niveau élevé de satisfaction, principalement dans leurs affirmations par rapport aux aspects qu'ils ont aimés. Les résultats du travail offrent des nombreux défis pour les musées et les écoles par rapport à la possibilité d’imaginer des projets éducatifs adaptés aux caractéristiques des enfants.

Mots clés:

Musées; enfants; école; étude du publique.

Fecha de recepción: 22-6-2016

Fecha de aceptación: 12-5-2018

\section{Introducción}

Los museos son instituciones sociales promotoras de experiencias particulares en las que se conjugan vivencias, emociones, conocimientos, objetos, relatos, narrativas y significaciones. Los museos reciben a una diversidad de públicos que asisten 'solos, acompañados o acompañando'. En este trabajo nos interesan los niños como público específico de los museos en el marco de una actividad educativa realizada en un museo de Argentina.

Según Pol y Asensio (2006) el público infantil ocupa un lugar importante en las audiencias reales de los museos españoles, sin embargo estas instituciones no suelen ofrecer propuestas y servicios acordes a sus necesidades. De manera similar Fernández (2002) señala que en los museos existe cierta creencia acerca de que los niños no están intelectualmente preparados para comprender temas específicos como el arte, o que no sabrán comportarse en las visitas. Por otro lado, Escribano (2015) señala que no todas las personas ven al museo de la misma manera, la 
percepción depende de sus ideas y experiencias previas, por ejemplo el público infantil puede visibilizar al museo como una vitrina llena de cosas que nos significan nada, de allí que resulta necesario trabajar con estrategias y recursos adecuados para lograr significar el patrimonio.

Si se pretende que los niños visiten museos, aprendan en ellos, tengas experiencias memorables (Alderoqui y Pedersoli, 2011), es necesario, tomarse el tiempo para conocer qué piensan de los museos, con quiénes asisten, cómo son sus experiencias, qué les gusta y qué no les agrada. Se considera a los museos como contextos creativos y poderosos para aprender (Elisondo y Melgar, 2015), por ello resulta importante trabajar en el diseño de propuestas e invitaciones que sorprendan a los pequeños, que disparen su curiosidad, actividades inesperadas (Elisondo, Rinaudo y Donolo, 2011) que generen recuerdos positivos. Señala Chávez (2015) que conocer las percepciones de los niños acerca de los museos amplía el panorama sobre la manera en que ellos conciben estas instituciones, permitiendo identificar cuáles son sus necesidades, generando información para crear y modificar programas para el público infantil.

El artículo se encuentra organizado en las siguientes secciones; problema de investigación y objetivos, antecedentes y fundamentación teórica, aspectos metodológicos, resultados y discusión y conclusiones.

\section{Problema de investigación y objetivos}

Considerando que los niños son un público frecuente de los museos, ya sea porque asisten con sus familias o porque acuden en visitas escolares, nos interesa conocer cuáles son las percepciones y experiencias que ellos tienen. Tanto a nivel nacional como local hemos encontrado escasas investigaciones que recuperen las percepciones de los niños en relación a los museos. La potencialidad de investigar las percepciones reside en contar con información que permita diseñar propuestas educativas y culturales diversas adecuadas a las expectativas de este público. El conocimiento de las percepciones también podría servir como fuente de información para los docentes que planifiquen experiencias educativas en los museos.

El estudio se plantea considerando la necesidad de poder conocer y analizar en el territorio local las percepciones, valoraciones e intereses de los niños para poder adaptar las estrategias del museo a este público. 
El principal problema que mueve la investigación es generar propuestas educativas y culturales apropiadas a las necesidades de los niños, potenciar el rol educador del museo, generar estrategias que permitan aprender en el museo desde propuestas lúdicas, educativas y culturales y contar con un corpus de información considerando el contexto local. Teniendo en cuenta estas ideas es que planteamos el trabajo de investigación realizado en el Museo Tecnológico Aeroespacial, ubicado en Las Higueras, Río Cuarto.

El Museo Tecnológico Aeroespacial recibe frecuentemente público infantil en el marco de visitas escolares, en general, estas tienen un formato tradicional. El director del Museo, en una entrevista, manifestó que tenían ciertas dificultades para adaptar las visitas al público infantil, por falta de formación específica. A partir de trabajos anteriores con el museo, se decidió colaborar en el diseño, implementación y evaluación de una actividad educativa y cultural para niños. Asimismo, en el marco de la actividad planificada, se proyectó una investigación para avanzar en el conocimiento de las percepciones y experiencias de los niños, que permita generar un corpus de información para potenciar las acciones del Museo Tecnológico, pero también para avanzar en el campo de los estudios de público en general, desde una perspectiva local. El conocimiento de las percepciones y experiencias de los niños se constituye en material para la gestión educativa y cultural de los museos, para adaptar las propuestas educativas a las expectativas y necesidades del público infantil.

El objetivo general de la investigación es conocer y analizar las percepciones y experiencias en museos de los alumnos (de nivel primario) de las escuelas (Colegio María Benita Arias, Colegio Nuestra Señora del Carmen, Escuela Jorge Newbery, Centro Educativo Poeta Lugones, Escuela Dr. Carlos Saavedra Lama) del (Departamento Río Cuarto, Córdoba, Argentina).

Los objetivos específicos son:

1 Conocer las percepciones de los alumnos (de nivel primario) de las escuelas (Colegio María Benita Arias, Colegio Nuestra Señora del Carmen, Escuela Jorge Newbery, Centro Educativo Poeta Lugones, Escuela Dr. Carlos Saavedra Lama) del (Departamento Río Cuarto, Córdoba, Argentina) respecto a cómo conciben los museos y qué actividades consideran que se desarrollan en ellos.

2. Describir las experiencias previas de los alumnos (de nivel prima- 
rio) de las escuelas (Colegio María Benita Arias, Colegio Nuestra Señora del Carmen, Escuela Jorge Newbery, Centro Educativo Poeta Lugones, Escuela Dr. Carlos Saavedra Lama) del (Departamento Río Cuarto, Córdoba, Argentina) en los museos, considerando con quiénes la realizan, en qué ocasiones y qué tipo de museos conocen.

3. Identificar las valoraciones que los alumnos (de nivel primario) de las escuelas (Colegio María Benita Arias, Colegio Nuestra Señora del Carmen, Escuela Jorge Newbery, Centro Educativo Poeta Lugones, Escuela Dr. Carlos Saavedra Lama) del (Departamento Río Cuarto, Córdoba, Argentina) realizaron de la actividad NAVE desarrollada en el Museo Tecnológico Aeroespacial teniendo en cuenta los aspectos que les agradaron, los aprendizajes percibidos y la satisfacción con la experiencia.

\section{Antecedentes y fundamentación teórica}

\subsection{Museos y niños}

Los niños aprenden diversas habilidades, conocimientos, valores y actitudes de los ambientes sociales en los que se desarrollan, en contacto con el medio familiar y social logran construir en poco tiempo herramientas para pensar, procesar y transformar la información de su entorno. Por ello, resulta relevante poder ofrecer experiencias significativas que propicien el conocimiento del mundo natural y social, así como el conocimiento de sí mismo (Casalins y Miranda, 2012).

Los museos son lugares de reunión, de relaciones sociales, de descubrimiento, de desarrollo de experiencias y de aprendizaje de habilidades, espacios de reflexión y concientización de los más jóvenes (Domínguez, 2003). Lugares de memoria, señala Hernández (2013), donde los recuerdos del pasado se convierten en una cuestión crítica del presente, en material para el ejercicio colectivo de la reflexión, lugares con ideología y posicionamientos que se convierten en medios de comunicación y difusión que promueven reflexiones. La actividad social es un eje central de las experiencias en museos (Alderoqui y Pedersoli, 2011).

Resulta clave para los museos que los niños tengan experiencias memorables, las buenas y tempranas experiencias influenciaran sus propias 
actitudes en la participación que después tengan junto con las de sus familias y amigos (Alderoqui, 2011). En este sentido, siguiendo la metáfora del efecto mariposa, las buenas experiencias en museos, actúan como aleteos, que pueden tener un gran impacto en la vida futura de quienes las vivencian (Alderoqui, 2008).

En la vinculación de los museos con los niños, parece que no todo es color de rosas, según Pol y Asencio (2006) persiste una mentalidad en la que los niños son vistos como un problema para la seguridad y la conservación de las colecciones; se observa falta de adecuación de los espacios según las características evolutivas de los jóvenes visitantes para hacer algo más que observar o mirar; se vislumbra una inadecuación de los contenidos expositivos y escasa programación destinada a los niños. Sin embargo, los museos realizan esfuerzos para atender a los pequeños visitantes.

Dufresne (2008) realiza un recorrido por la evolución de la educación museal dirigida a los niños y adolescentes en los últimos 50 años. En su reconstrucción enfatiza las características de los educadores de museos frente al público infantil, como "profesionales abiertos a múltiples influencias; curiosos; flexibles y creativos; dinámicos; críticos; rigurosos; capaces de colaborar para exportar sus intervenciones fuera del museo" (p. 57). Queda como desafío para la autora reforzar las colaboraciones existentes entre escuelas y museos, familias y museos, universidad y museo para hacerlas más permanentes y fructíferas.

¿Qué características tendrían que tener los museos para adaptarse a las necesidades del público infantil? Deberían ofrecer la oportunidad de poner en contacto a los niños con objetos del mundo social y natural a través de la experimentación, el juego y la invención (Alderoqui de Pinus, 2006; Maceira, 2008; Alderoqui y Pedersoli, 2011; Casalins y Miranda, 2012, Melgar y Tuninetti, 2017). Alderoqui de Pinus (2006) retomando el Modelo Contextual del Aprendizaje (Falk y Dierking, 2000) propone una serie de consideraciones para promover experiencias significativas entrelazando los contextos físico, social y personal.

Contexto físico. Cuando se trabaja con niños resulta necesario ofrecer un contexto oportuno que propicie la comprensión. Un aspecto que ayuda a la construcción de conocimientos es la experiencia directa y la manipulación de los objetos que han sido elegidos para responder a las necesidades evolutivas, también colabora con el aprendizaje la exploración del ambiente por medio de los sentidos (Alderoqui de Pinus, 2006). 
Contexto social. Muñoz (2016) señala que desde un enfoque sociocultural del aprendizaje en los museos, debe trabajarse en asegurar ocasiones donde se pueden emplear los recursos individuales, sociales y culturales para lograr metas, reconociendo el papel significativo de los padres y maestros, como apoyo para extender y enriquecer la actividad de los niños por medio de la asistencia y la conversación. Es necesario ofrecer textos explicativos de los contenidos y orientaciones del lugar para que los adultos puedan acompañar a los pequeños (Alderoqui de Pinus, 2006).

Contexto personal. Resulta conveniente trabajar de manera explícita en el desarrollo de respuestas afectivas que incluyan intereses, actitudes y emociones de los niños. El diseño de dispositivos, exposiciones y actividades con propósitos educativos puede colaborar en este sentido (Alderoqui de Pinus, 2006).

En el siguiente apartado presentamos algunas investigaciones realizadas con niños en las que se consideran sus percepciones y experiencias. Señalan Pol y Asensio (2006) es necesario recuperar la voz de los niños, ya que ellos "saben perfectamente lo que les gusta y lo que no y por qué" (p. 13).

\subsection{Estudios de percepciones y experiencias de niños en museos}

En esta sección se presentan estudios realizados en diferente partes del mundo que recuperan la voz de los niños. Anderson et al (2002) realizaron un estudio de caso con el objetivo de identificar mediadores que favorezcan el aprendizaje de los niños en los museos. La investigación se desarrolló en cuatro museos; uno de historia natural y social, una galería de arte, un centro interactivo de ciencia y uno de historia social del arte. Participaron de la investigación cuatro grupos escolares ubicados en la franja etaria de 4 a 6 años, unos 99 niños y niñas en total. Para la recolección de datos se emplearon diversas técnicas como observaciones de las interacciones de los niños en los museos y entrevistas, entre otros.

De los resultados se destaca; la diversidad de intereses y recuerdos de los niños que da cuenta del carácter único de la experiencia para cada sujeto. La diversidad se observó tanto en los recuerdos espontáneos como en aquellas experiencias consideradas memorables y divertidas. Los pequeños recordaron más las exhibiciones a gran escala principalmente cuando se asociaron con efectos cenestésicos y experiencias tác- 
tiles; los contenidos que fueron contados como historias, y las propuestas de los facilitadores que apelaban a recursos teatrales e incluyeron otros recursos como audiovisuales, diapositivas y objetos. Por otro lado se observaron ciertas dificultades para establecer relaciones entre las experiencias en los museos y las escuelas. Además de los mencionados, otros mediadores interesantes para el aprendizaje de los niños en los museos son las actividades que ellos desarrollan en sus ambientes cotidianos tales como jugar, saltar, tocar, cavar en la arena y aquellas que ofrecen posibilidades de contextualización, que pueden conectarse con sus historias y experiencias de vida.

Otro estudio cualitativo fue el realizado por Unal (2012) que tuvo por objetivo investigar los intereses y percepciones de niños entre 4 y 8 años acerca de sus experiencias en un museo y con los objetos. Participaron del estudio 12 niños (3 niñas y 9 niños) que visitaron el Museo Antalya con sus familias o como miembros de su grupo escolar. Los investigadores realizaron observaciones participantes intentando identificar qué hacían los niños y a qué prestaban atención.

Los resultados del estudio de Unal (2012) permitieron conocer que los niños prestaron especial atención a estatuas, esculturas y tumbas, pero también a otros objetos tales como monedas de oro y plata, marfil, botellas con forma de ojo, entre otros. Realizaron preguntas que indagaron sobre la apariencia del objeto, la calidad original, la forma en que se exhiben, cómo se conservan y reparan y si existen objetos similares en el resto del museo. Por otro lado, reaccionaron de diferentes maneras, algunos mostraron aprobación frente a los objetos, otros miedo (principalmente con algunos objetos asociados con la muerte como esqueletos) y también reaccionaron con risas (por ejemplo frente a las estatuas desnudas o aquellas que les faltaban alguna parte). En general los niños estuvieron atentos, hicieron comentarios, recordaron experiencias previas y desarrollaron sugerencias.

En sus percepciones sobre el museo algunos expresaron su aburrimiento durante la visita, mientras que otros mencionaron que el museo era hermoso y que les gustaría visitarlo de nuevo. En general, los niños cumplen con las reglas del museo, los adultos que acompañan actúan como apoyo para que los jóvenes se comporten como deben. Los pequeños suelen permanecer más tiempo en las áreas que les interesan y realizan preguntas sobre los objetos que Ilaman su atención (Unal, 2012).

Chávez (2015) realizó un estudio cualitativo con 16 niños en el Mu- 
seo Nacional de Culturas Populares (MNCP) en la localidad de Coyoacán, México. El objetivo de la investigación fue conocer las percepciones del público infantil sobre un curso de verano realizado en el museo. La franja etaria de los niños que participaron del estudio se ubicó entre los 7 y 9 años. Para la recolección de información se emplearon entrevistas y análisis de dibujos.

Los resultados de la investigación de Chávez (2015) permitieron identificar que los niños conciben a los museos de dos maneras principalmente, una ligada a las actividades que desarrollaron durante el curso de verano, "lugar en el que juegan y se divierten con sus amigos; un espacio en donde los prestadores de servicio les enseñan y ayudan a hacer sus actividades" (p. 56), y otra en donde "el museo es concebido como un espacio cultural en donde se exponen cosas del pasado, que sirve para adquirir conocimiento sobre algún tema" (p. 64)

Por otro lado fue posible observar el tipo de relaciones sociales que se establecen en el museo, los niños generaron vínculos afectivos con otros pequeños y con los educadores del museo; quienes tiene un rol esencial para promover lazos de confianza y amistad que los incentiva a realizar las actividades programadas (Chávez, 2015). Entre las actividades que más les gustaron se destacaron hacer, crear, tocar, jugar y experimentar con materiales diversos. En relación con las que no les gustaron señala Chávez (2015) que el desagrado se experimenta en las sensaciones que individualmente tienen al entrar en contacto con ciertos materiales y el grado de dificultad que para los niños representa la elaboración de algunas actividades. Cuando se preguntó qué actividades les gustaría hacer destacaron algunas artísticas como danza, obras de teatro y elaboración de artesanías.

En el Museo Quimbaya de Colombia también se realizó un estudio que recupera la voz de los más jóvenes (Castro, 2003). Como parte del proceso de diseño de una sala didáctica se consultó a un grupo de 17 niños y niñas ubicado en edades entre 9 y 12 años de diferentes lugares y estratos sociales de la ciudad de Armenia y un grupo de observadores adultos. Los resultados indicaron que los niños percibieron a los museos en función de sus experiencias previas y particulares, siendo frecuente la idea del museo como lugar para leer, ya que varios de los pequeños fueron visitantes asiduos del espacio y participaron de las salas de lectura.

Respecto de las percepciones sobre qué tiene un museo dentro, los niños mencionaron: cosas, únicas, con valor e importantes, viejas, socia- 
les, naturales, modernas y antiguas. Considerando las funciones de los museos señala Castro (2003) que en las representaciones de los niños se reconocen las principales misiones: educación, estudio y disfrute. Finalmente, los niños consultados en este estudio mencionaron que conocían otros museos, cercanos a sus localidades, otros emblemáticos de Colombia y algunos relacionados a experiencias en los espacios escolares, o familiares (por ejemplo museos de niños).

\section{Metodología}

La metodología empleada en el estudio se presenta considerando el contexto y los sujetos del estudio, el instrumento y procedimiento de recogida de datos y el procedimiento de análisis de datos. Se realizó un estudio mixto combinando un enfoque cualitativo y cuantitativo. Se atendieron los aspectos éticos y se tomaron los recaudos y cuidados necesarios para resguardar el anonimato y la confidencialidad de los datos.

\subsection{Contexto y sujetos de estudio}

La investigación se desarrolló en el marco de una actividad realizada en el Museo Tecnológico Aeroespacial (MTA en adelante), denominada NAVE: viaje por el sistema solar diseñada especialmente para estudiantes de 5 to y 6to grado de primaria. El MTA está ubicado en el Área de Materiales de la Fuerza Aérea Argentina de la localidad de Las Higueras (Argentina). Considerando las posibilidades edilicias del MTA, especialmente en su muestra las características físicas del aire, se decidió generar una actividad destinada a niños que ofreciera una experiencia diferente a la tradicional visita guiada y que además estuviese relacionada a contenidos escolares.

NAVE es una propuesta diseñada por el Observatorio Astronómico de la ciudad de Córdoba que se realizó por primera vez en la Noche de los Museos en dicha ciudad. A partir de NAVE se generó una nueva invitación que involucró otras acciones y actividades para los niños. Participaron de la organización la Universidad Nacional de Río Cuarto, el MTA y el Observatorio Astronómico de Córdoba. La propuesta quedó estructurada en tres partes: a) Viaje por el sistema solar, en un escenario ambientado con humo, luces de colores, y sonidos que intentaba simular el 
interior de una nave espacial y su tablero de comando, los responsables de la actividad invitaron a los niños a ubicarse y luego se presentaron. Más tarde, comenzó la proyección de un video y un astrónomo guiaba la experiencia, relatando el viaje. b) Los planetas y sus características, un grupo de estudiantes de diferentes carreras de la UNRC, denominado Descubrí Experimentando, organizó actividades que ampliaban algunos de los contenidos trabajadores en el viaje. A modo de recuerdo se entregaron papeles con curiosidades sobre los planetas. c) Explorando el museo al aire libre, los niños pudieron realizar exploraciones del parque del museo, se subieron a los aviones, corrieron, observaron cómo se entrenan los perros en el Área de Materiales, disfrutaron del espacio natural de manera libre.

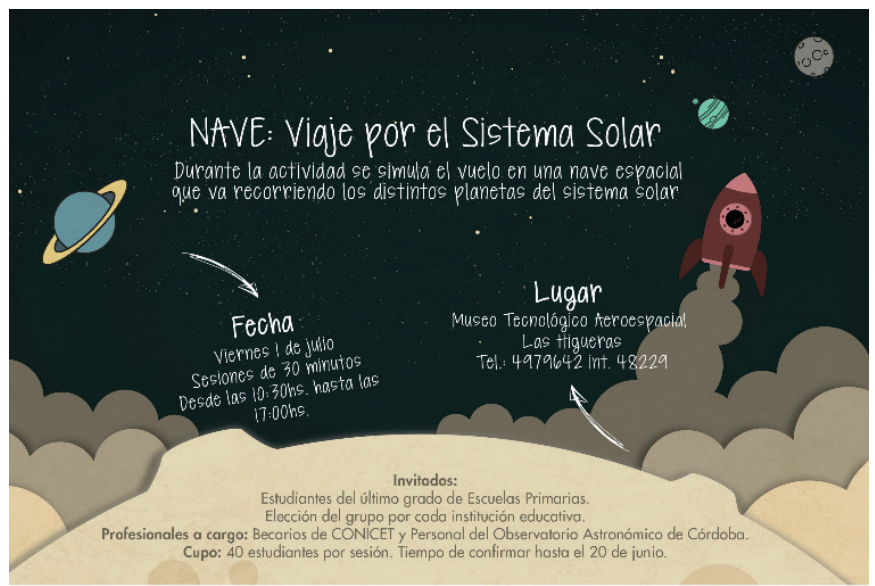

Figura 1. Flyer de la actividad NAVE en Río Cuarto.

Fuente. Museo Tecnológico Aeroespacial- Universidad Nacional de Río Cuarto.

Participaron del estudio 133 niños de las siguientes instituciones, de gestión estatal y privada, urbanas y rurales: Colegio María Benita Arias (31 sujetos); Colegio Nuestra Señora del Carmen (28 sujetos); Escuela Jorge Newbery (34 sujetos); Centro Educativo Poeta Lugones (8 sujetos); Colegio Evangélico Nueva Argentina (19 sujetos); Escuela Dr. Carlos Saavedra Lama (13 sujetos), todas ubicadas en la ciudad de Río Cuarto y la región (Departamento de Río Cuarto, Córdoba, Argentina). Las edades de los niños estuvieron comprendidas entre los 8 a los 13 años, ubicándose la mayoría en la franja etaria de los 11 años (108 sujetos). En relación a la distribución según sexo, se observó que hubo más niñas 
¡Todo me gustó! Los niños y sus percepciones de una actividad educativa en un museo

(88 sujetos) que niños (45 sujetos). Respecto de los grados escolares que participaron de la propuesta la mayoría de los niños cursaban 6to grado (124) y en menor medida, también participaron estudiantes de 5to grado (7sujetos) y de 3 ro y 4 to grado (2 sujetos).

\subsection{Instrumento y procedimiento de recogida de datos}

Se empleó un cuestionario organizado en ítems que requirieron respuestas cerradas y abiertas. Se recogieron datos acerca de la edad, el grado y pertenencia escolar y el género de los niños. El cuestionario se estructuró en diez apartados. El apartado 1 tenía por objetivo recoger información acerca de las percepciones de los niños sobre los museos. Se consultó a través un ítem de respuesta abierta ¿Qué es un museo?

El apartado $2^{2}$ tenía por objetivo recoger información acerca de las actividades que los niños perciben que se desarrollan en un museo. Se proponía un ítem con opciones de respuestas cerradas. Con el enunciado el Museo es un lugar donde... Se ofrecieron las siguientes opciones: se aprende, te cuentan historias y sientes cosas, se disfruta, donde hay que hacer silencio, te entretienes, ves objetos (cuadros, pinturas, esculturas), te aburres, te quieres ir pronto, te cansas y no voy. Los niños podían elegir, una o más opciones.

El apartado $3^{3}$ tenía por propósito conocer las percepciones de los niños acerca de para qué sirve visitar un museo. El ítem presentaba opciones de respuesta cerrada. El enunciado que se presentó a los pequeños fue Visitar un museo sirve para..., y las opciones de respuestas fueron; aprender, conocer, aburrirse, divertirse, distraerse, salir de la escuela. Se podía elegir una opción o más opciones.

El apartado 4 tenía por objetivo conocer con quiénes van los niños al museo. Se presentó un ítem con dos opciones de respuesta; la familia y la escuela. Los chicos podían elegir, una o ambas opciones.

El apartado 5 recogía información acerca de las ocasiones en las que los pequeños visitan museos. Se presentó un ítem con las siguientes opciones de respuesta: en vacaciones con mi familia, en algún viaje, con la

2 Para su redacción nuestro equipo tomó como base el instrumento empleado por el Laboratorio Permanente de Estudio de Público (2013) presentando en su estudio Conociendo a todos los públicos ¿Qué imágenes se asocian a los museos?

3 Para su redacción nuestro equipo tomó como base el instrumento empleado por el Laboratorio Permanente de Estudio de Público (2013) presentando en su estudio Conociendo a todos los públicos ¿Qué imágenes se asocian a los museos? 
escuela, cuando tengo ganas le pido a un adulto que me acompañe. Los niños podían elegir una o más opciones.

El apartado 6 consultaba si los niños conocían otros museos y cuáles. Se presentó un ítem con respuesta abierta ¿Has visitado otros museos además de este? ¿Cuáles?

Los apartados 7, 8, 9 y 10 tenían por objetivo recoger información acerca de las valoraciones que los niños realizaron de la actividad de la que participaron en el museo. Se consultó a través de los siguientes ítems, todos de respuesta abierta: ¿Qué fue lo que más te gustó de la actividad que hicimos hoy en el museo?, ¿Qué aprendiste? , ¿Qué no te gustó? y ¿Volverías a este museo? ¿Por qué?

Una vez finalizada la actividad, se entregó el cuestionario a los niños y se explicó cómo debían completarlo con ayuda de los docentes. Se contó con la autorización de los maestros y directivos para consultar a los niños en el proceso de investigación. Se tomaron los recaudos necesarios para preservar la confidencialidad y el anonimato de los mismos.

\subsection{Análisis de datos}

Para ello se empleó una plantilla de Excel. Las categorías centrales construidas para este estudio son: percepciones sobre los museos; experiencias previas en museos y valoraciones de una actividad destinada a público infantil.

\section{Resultados y discusión}

Se presentan a continuación tres categorías con sus subcategorías que son analizadas considerando investigaciones previas y perspectivas teóricas que fundamentan el estudio.

\subsection{Percepciones sobre los museos}

Las percepciones de los niños consultados acerca de los museos pueden presentarse considerando tres aspectos; qué es para ellos un museo, qué actividades consideran que se hace en los museos y para qué sirve visitar un museo.

Un museo es. A partir de las respuestas de los niños fue posible ob- 
servar que conciben al museo principalmente de tres maneras: a) lugares donde se muestran, exhiben, exponen y guardan 'cosas' y 'objetos' 'antiguos' importantes para la 'historia' o para el pasado (75 sujetos, 56\%); b) lugares para aprender, observar, informarse y conocer (47 sujetos, 35\%) y c) lugares para disfrutar, divertirse, lindos (4 sujetos, $3 \%$ ). No respondieron el ítem 7 sujetos (5\%). En la Figura 1 se presentan las concepciones más frecuentes de los niños. Compartimos algunos fragmentos de las respuestas acerca de ¿Qué es un museo?

Un museo es un lugar que te muestra cosas de la historia, de la antigüedad y objetos que nunca vimos (Niña, 11 años).

Un museo es un lugar donde la gente puede ir a ver o informarse de cosas o aprender, depende del tema del museo (Niña, 11 años).

Conocer, divertirse y aprender (Niña, 11 años).

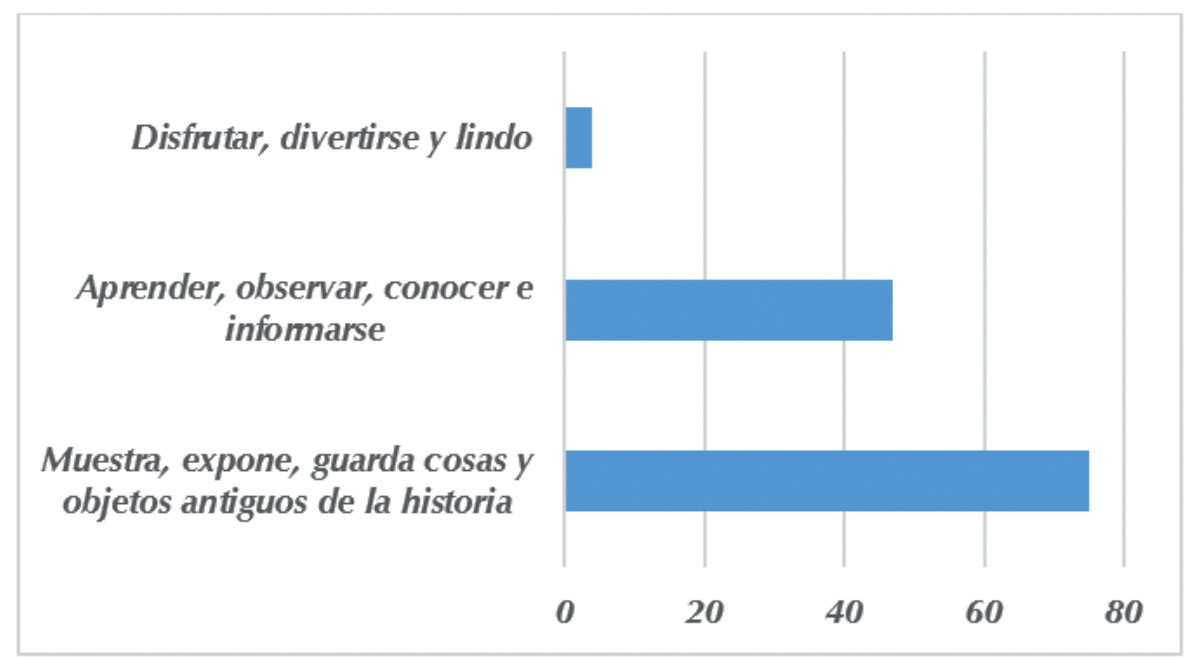

Figura 1. Percepciones de los niños acerca de ¿Qué es un museo?

Resultados similares fueron señalados por Castro (2003) y Chávez (2015), en general los niños perciben a los museos como lugares vinculados a objetos y cosas, relacionados con la historia y el pasado, que son 'importantes y valiosos para nosotros'; en ellos es posible conocer, aprender y observar; son lugares lindos, para disfrutar. Se destacan dos aspectos, por un lado como señala Castro (2003) en las diferentes percepciones acerca de los museos pueden verse representadas las funcio- 
nes educativas, de estudio y de disfrute; y por otro lado como menciona Hein (1998) los sujetos construyen significados en sus experiencias en museos, todos los niños consultados definieron al museo de alguna manera. La percepción de los museos como espacios de conservación y exposición de objetos culturales e históricos también ha sido frecuente en grupos de jóvenes estudiados en otras ocasiones (Melgar, 2017).

Un museo es un lugar donde. Considerando las respuestas al apartado 2, en general los niños percibieron a los museos como lugares donde: a) aprenden (125 sujetos, 94\%), b) ven y observan objetos (94 sujetos, $71 \%$ ), c) disfrutan (81 sujetos, $61 \%$ ), se entretienen (49 sujetos, 50\%), d) se relatan historias ( 74 sujetos, $56 \%$ ) y e) hay que hacer silencio ( 49 sujetos, 37\%). Cabe destacar que de los 133 sujetos, ninguno eligió la opción te quieres ir pronto, solo 3 sujetos (2\%) eligieron la afirmación te cansas, y 2 sujetos ( 1\%), la opción te aburres. En el Figura 2 se observan las frecuencias de cada respuesta.

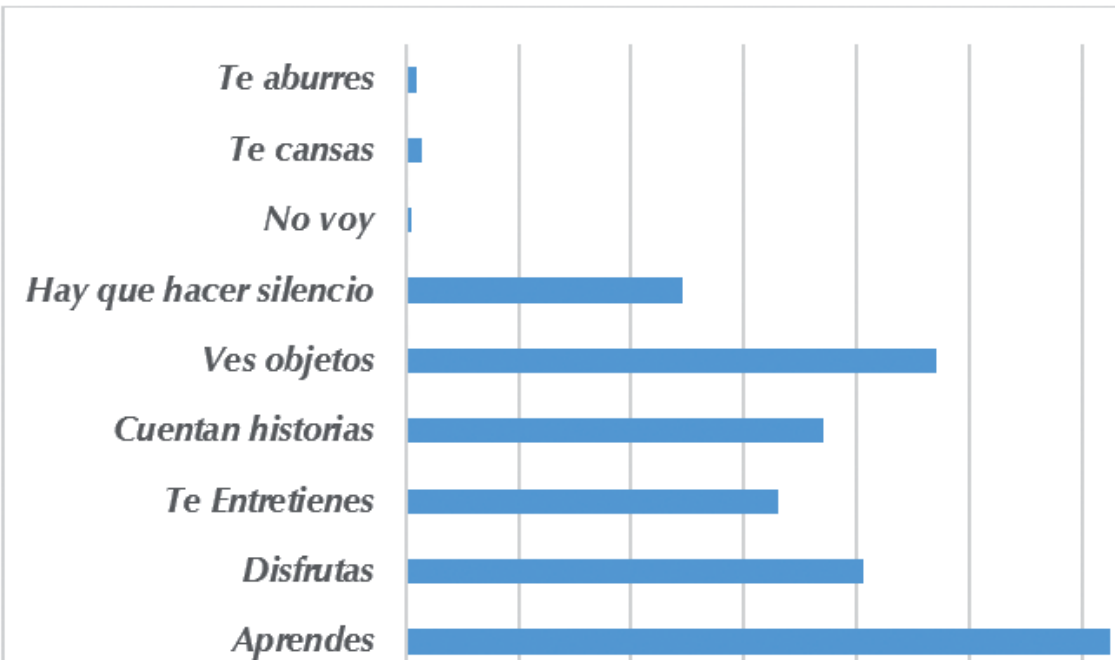

Figura 2. Un museo es un lugar donde...

En este sentido, considerando la satisfacción con la visita el Laboratorio Permanente de Estudios de Público (2013) en un estudio realizado con adultos encontró que en general las personas se muestran satisfechas con su experiencias en los museos, destacan que son vivencias agradables donde pudieron aprender, disfrutar y conocer.

Los niños se presentan como visitantes activos, construyen significa- 
dos de sus experiencias, disfrutan y los entretiene visitar museos, reconocen que en estos espacios aprenden, observan, escuchan historias, y también respetan las reglas de la institución por ejemplo en los momentos que hay que hacer silencio. Los niños muestran satisfacción con su experiencia, se destaca que ninguno eligió la opción de querer irse pronto del museo. Unal (2012) observó que los niños presentan intereses diversos sobre el ambiente del museo, en general cumplen con las reglas de comportamiento y suelen permanecer más tiempo en aquellos espacios que les llaman la atención.

Visitar un museo sirve para. Según las percepciones de los niños un museo sirve para a) aprender (129 sujetos, 97\%), b) conocer (119 sujetos, $89 \%$ ), c) divertirse (77 sujetos, 58\%), d) distraerse (23 sujetos, 17\%) y e) salir de la escuela (17 sujetos, 13\%). Los niños consultados en este estudio configuraron principalmente a los museos como contextos para aprender y conocer. Lejos de percibirlos como lugares aburridos señalaron que en los museos pueden divertirse y distraerse. Otro aspecto a destacar es que algunos mencionaron que este tipo de experiencias les permiten salir de la escuela. La Figura 3 muestra las respuestas más frecuentes.

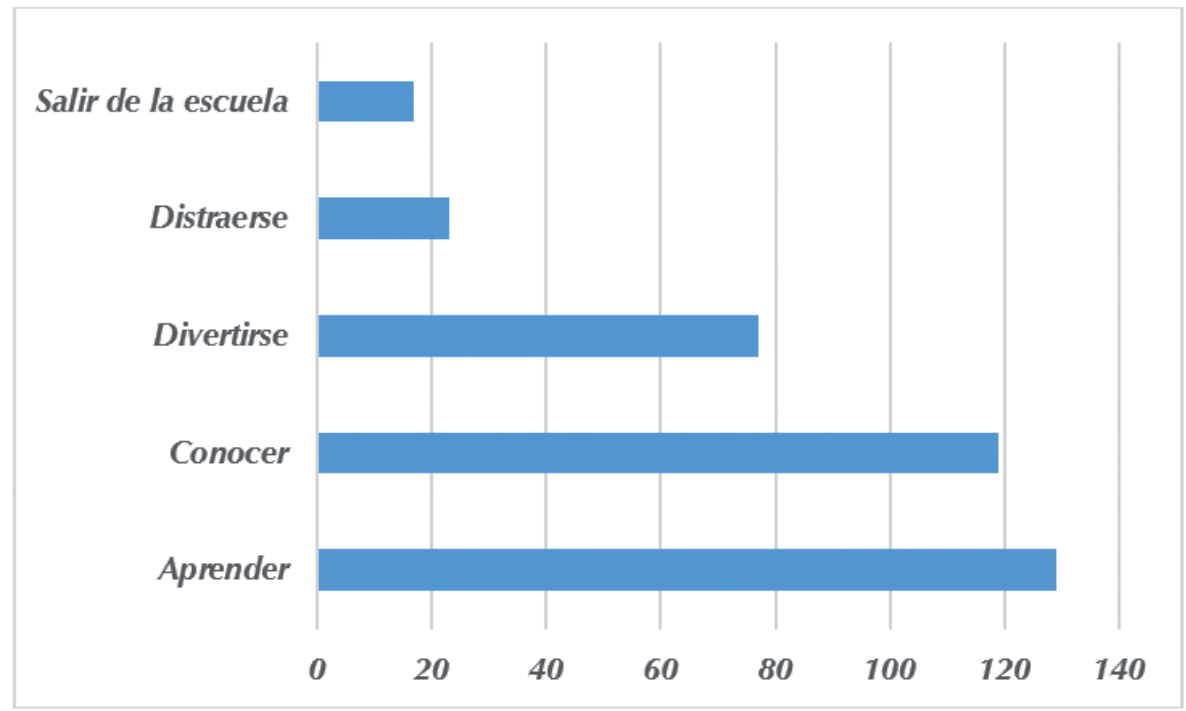

Figura 3. Visitar un museo sirve para... 


\subsection{Experiencias previas en museos}

En relación con las experiencias en museos nos interesaba identificar si los niños conocían con anterioridad otros museos y además con quienes y en qué circunstancias los visitaban.

De los 133 niños, 86 sujetos (65\%) señalaron que sí conocían otros museos, y 48 sujetos (36\%) mencionaron no conocer. Un sujeto no respondió el ítem y otro mencionó no recordar si conocía otro museo. Los que sí conocían mencionaron museos referidos a lugares específicos (Río Cuarto, Córdoba, Achiras, Mina Clavero, Rosario entre otros), disciplinas científicas y artísticas (arte, historia, ciencias naturales), objetos (autos, dinosaurios) y de niños (Barrilete). Resultados similares encontró Castro (2003) cuando los niños señalaron que sí conocían previamente museos cercanos a sus localidades, otros emblemáticos de Colombia y algunos relacionados a experiencias en los espacios escolares o familiares.

En relación con lo que se comprende como contexto social de la experiencia en museos, los niños indicaron con mayor frecuencia que los visitaron con la escuela (129 sujetos, 97\%) y en segundo lugar con la familia (66 sujetos, 50\%). Este dato resulta relevante ya que pone en relieve el papel de la escuela como promotora de prácticas culturales, oferente de nuevos contextos para aprender y disfrutar, y responsable de garantizar el derecho a la educación. En investigaciones previas se encontraron resultados, en los que la escuela aparece como promotora de nuevas experiencias de aprendizaje en contextos museísticos (Melgar, 2017, Melgar y Elisondo, 2017)

Los niños señalaron que visitaron museos en diferentes circunstancias siendo los más frecuentes viajes con la escuela (130 sujetos, 98\%) y vacaciones con la familia (33 sujetos, 25\%). Además, fue interesante observar que algunos indicaron la opción cuando tengo ganas de visitar un museo le pido a un adulto que me acompañe (13 veces, 9,8\%) aspecto que refuerza la idea de los niños como sujetos activos en la búsqueda de aprendizajes y experiencias. La información acerca de las circunstancias se complementan con aquella que se relaciona con quiénes visitan los niños museos. Nuevamente escuela y familia, aparecen como apoyos relevantes a la hora de promover experiencias en museos. En la Figura 4 se muestran las respuestas más frecuentes sobre las circunstancias en que los niños visitan museos. 


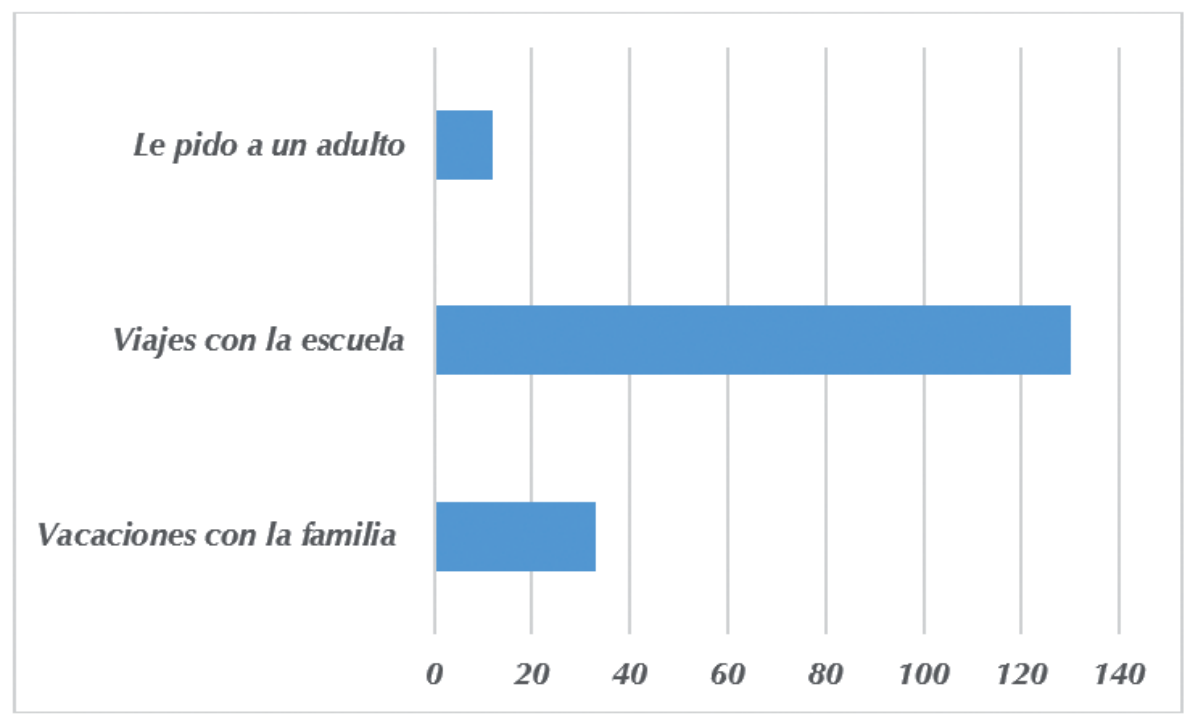

Figura 4. Experiencias previas en museos ¿en qué circunstancias?

Recuperar la voz de los niños identificando en sus palabras que muchos conocen museos a partir de las acciones y propuestas desarrolladas por las escuelas resulta relevante para seguir, en término de Elisondo (2015) aumentando y abriendo la educación, generando ocasiones para que las personas desde contextos como la escuela o la universidad puedan ampliar sus interacciones con artefactos de la cultura, interactuar con otros, conocer nuevos espacios culturales, seguir apostando a salir del aula y aprender de otros contextos (Melgar y Donolo, 2011). Aumentar y abrir la educación, implica también en términos de Badilla (2007) descentralizarla, abrir espacios para que los aprendices puedan hacerse cargo de su propio aprendizaje.

\subsection{Valoraciones de una actividad destinada a público infantil}

Además de conocer cómo perciben los niños los museos y qué experiencias previas han tenido en ellos, nos interesaban las valoraciones que ellos realizaron de la actividad NAVE. A partir de sus respuestas construimos tres subcategorías acerca de las valoraciones de los niños: a) los aspectos que destacaron de la propuesta, b) los aprendizajes percibidos y c) la satisfacción con la experiencia que incluye sugerencias y modificaciones de la propuesta. 
Aspectos destacados. Los niños destacaron los siguientes aspectos como aquellos que más les agradaron; a) experimentar -subir al avión, hacer las actividades-; b) conocer más sobre un contenido -universo, sistema solar, galaxias, distancias entre los planetas, gravedad, entre otros-; c) la presentación a través de un audiovisual -el video que mostraba el viaje- y d) el entrenamiento de los perros. También se mencionaron otros tales como 'la explicación del chico', 'lo que decían de los planetas', 'la charla', 'compartir con mis amigos'. La Figura 5 muestra una nube de palabras con los aspectos destacados por los niños. A continuación compartimos algunas respuestas de los pequeños.

Me gustó aprender sobre el universo (Niña, 15, 11años)

Subir al avión (Niña 4, 11 años)

Lo que más me gustó es cuando nos mostraban los planetas (Niña 16, 11 años) La actividad con los perros (Niño 56, 11 años)

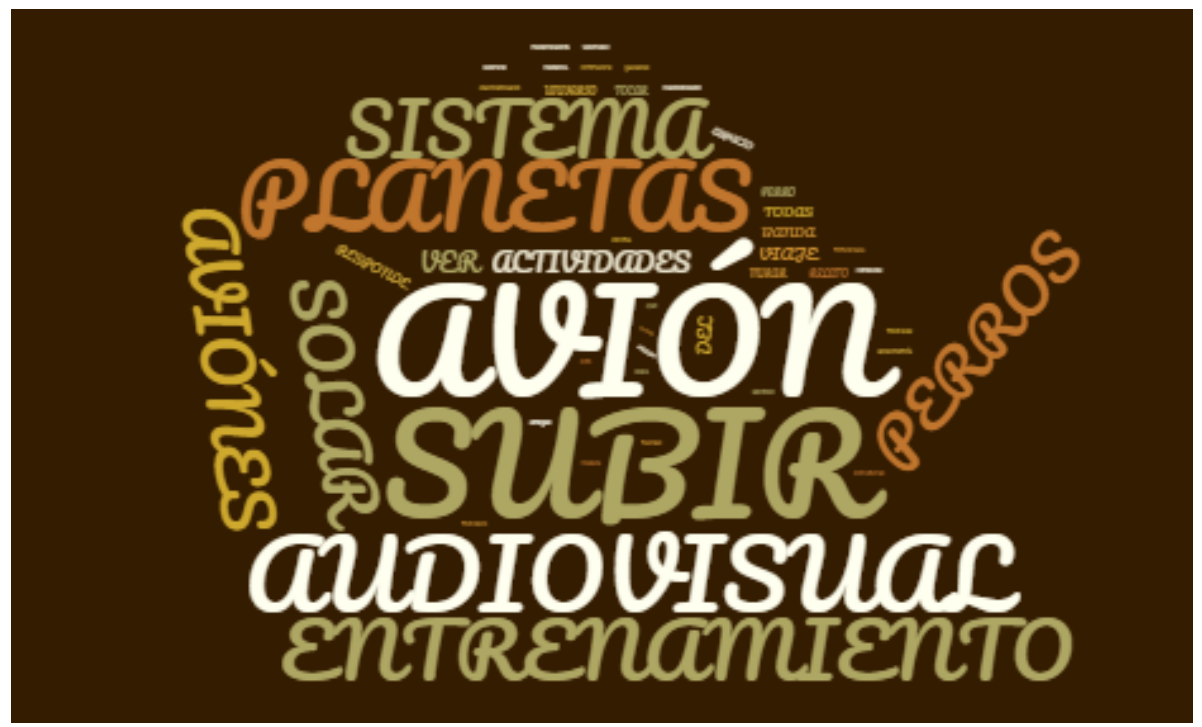

Figura 5. Aspectos destacados por los niños de la actividad Nave. Fuente. Elaboración propia.

Diversos son los aspectos destacados, conocer más sobre un tema, experimentar, la presentación a través de audiovisuales, lo que cuenta el guía, ver como se entrenan los perros. Anderson (2002); Unal (2012) y Chávez (2015) encontraron resultados similares en los que los niños 
¡Todo me gustó! Los niños y sus percepciones de una actividad educativa en un museo María Fernanda Melgar

valoraron actividades vinculadas a la experimentación, tocar, jugar, hacer; así como aquellas presentaciones con una narrativas cercana, relatada de modo ameno. Por otro lado en término de Anderson (2002) se observó una diversidad de intereses y recuerdos en los niños; un mayor recuerdo de las exhibiciones a gran escala principalmente cuando se asociaron con efectos cenestésicos y experiencias táctiles por ejemplo subir al avión; y además se vislumbró que recuerdan más aquellas experiencias que se presentan como 'historias, narraciones'.

Aprendizajes. Esta subcategoría se construyó a partir de las respuestas abiertas de los niños al apartado 8. En relación con los aprendizajes, los señalados con mayor frecuencia fueron aquellos referidos a informaciones y contenidos vinculados a los a) planetas y el sistema solar, b) aviones y c) muchas cosas. En la Figura 6 se presenta una nube de palabras acerca de los aprendizajes que mencionaron los niños. Compartimos algunos ejemplos de respuestas:

Las distancias que hay entre los planetas y sus características (Niña 3, 12 años)

Sobre la masa, el peso, la gravedad y el sistema solar (Niña 132, 11 años) Sobre los aviones (Niña 55, 10 años)

Muchas cosas (Niño 12, 11 años)

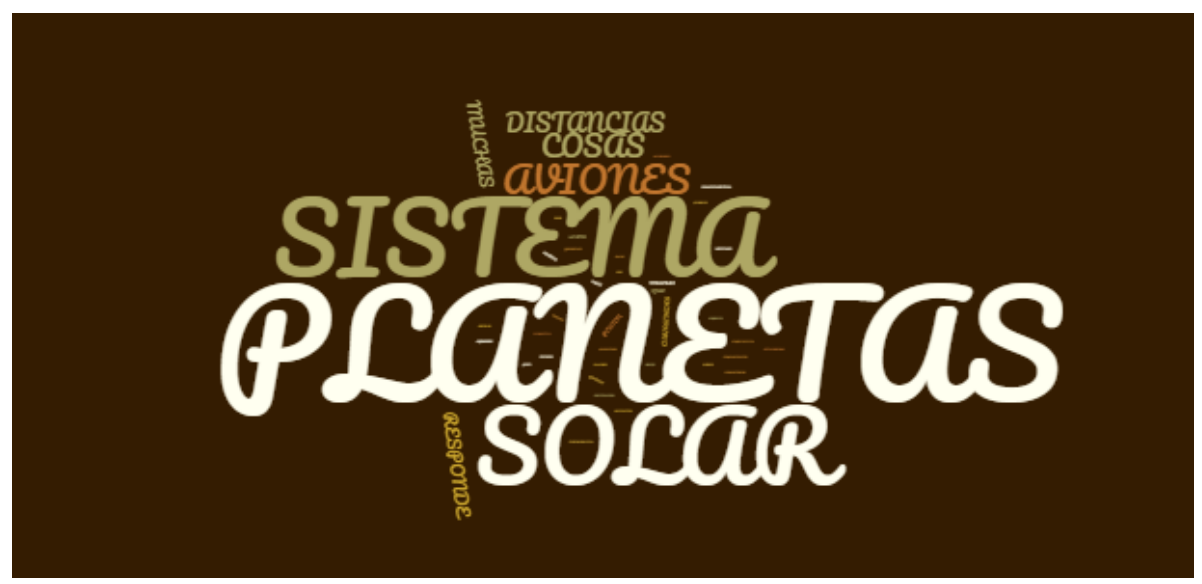

Figura 6. Percepciones de los niños acerca de sus aprendizajes. Fuente. Elaboración propia. 
Los principales aprendizajes que mencionaron los niños estuvieron relacionados a contenidos escolares y en sus palabras la visita al museo sirvió para 'aprender más' de un contenido específico. Este resultado es diferente al encontrado por Anderson et al. (2002) quien señaló que se observaron escasas vinculaciones entre las experiencias en los museos y en las aulas, solo unos pocos casos los niños recordaron y discutieron lo que veían en el museo con lo trabajado en las clases. Finalmente la idea que los niños enuncien ciertos contenidos, se relaciona a la posibilidad de complementación de propuestas entre museos y escuelas (Dujovne, 1995; Aguirre y Vázquez, 2004; Guisasola y Morentin, 2007).

Satisfacción con la visita. Esta subcategoría se construyó a partir de las respuestas abiertas de los niños a los apartados 9 y 10 del cuestionario. Se consultó a los niños qué aspectos modificarían de la actividad, de los 133,112 sujetos (84\%) señalaron que todo les gustó, que no modificarían nada. Los aspectos que modificarían los niños incluyen quitar el video de Paka-Paka como apoyo a las actividades de Descubrí Experimentando; la escena del comedor con los soldados en la muestra permanente del museo porque les dio miedo; que otros chicos hablaban y no hacían silencio y tener que esperar entre las actividades. No respondieron el ítem 4 sujetos (3\%). A continuación compartimos algunos ejemplos de respuesta.

Nada, me gustó todo (Niña 1, 11 años)

Nada todo estaba bien, divertido (Niña 5, 11 años)

Las estatuas de los hombres no me gustaron, es que me dieron un poco de miedo (Niña 41, 11 años).

El video de las distancias de los planetas de Paka-Paka (Niña 61, 11 años)

Que cuando explicaban algunos chicos hablaban (Niña 76, 11 años)

Nada, ¡Todo me gustó! Fue la respuesta más frecuente ofrecida por los niños consultados, sirviendo como indicador del grado de satisfacción con la experiencia. Este resultado, permite seguir apostado a generar invitaciones diseñadas para públicos específicos. Los visitantes de todas las edades valoran sentirse agasajados por los museos. Según el Laboratorio Permanente de Estudio de Público (2012) las personas "esperan ser sorprendidas, que el museo despierte su curiosidad a través de una oferta

4 Es un canal infantil público y educativo operado por el Ministerio de Educación de la República Argentina. http://www.pakapaka.gob.ar/ 
novedosa" (p. 61) que les permita descubrir cosas nuevas. Por otro lado en relación con los aspectos que nos les agradaron, Chávez (2015) en su estudio observó que el desagrado se relaciona con las sensaciones particulares que cada sujeto vivenció al entrar en contacto con materiales específicos o considerando el grado de dificultad que ciertas actividades les representaron lo que provocó en algunos casos abandono de la actividad, resultando estas experiencias negativas.

La última pregunta del cuestionario indagaba si los niños volverían en el futuro al museo. De los 133 niños, 131 sujetos (99\%) mencionaron que sí regresarían al museo, y 2 sujetos (1\%) señalaron que no volverían, principalmente porque no podrían hacerlo solos, es decir, sin que la escuela los lleve. Este aspecto podría indicar un amplio grado de satisfacción con las experiencias expresado en el deseo de querer regresar al museo.

\section{Conclusiones y prospectiva}

A modo de conclusión retomamos los principales resultados del estudio según los objetivos que nos planteamos. En relación a las percepciones de los niños sobre el museo, las actividades que pueden realizar en ellos y los objetivos de las visitas pudimos observar que en este y otros estudios (Castro, 2003; Chavéz, 2016; Anderson et al., 2002; Unal, 2012) los museos son percibidos de manera positiva por los niños, como lugares para aprender, conocer, entretenerse, divertirse y salir del aula. Tres concepciones fueron las más frecuentes en este estudio; los museos como lugares donde se muestran, exhiben, exponen y guardan 'cosas' y 'objetos' 'antiguos' importantes para la 'historia' o para el pasado; como lugares para aprender, observar, informarse y conocer, y como lugares para disfrutar y divertirse. Los niños consultados en este estudio configuraron principalmente a los museos como contextos para aprender y conocer.

Los resultados del estudio en torno a las percepciones de los niños sobre los museos, desafían a estas instituciones en término de generar experiencias que permitan concebir el museo como un espacio vinculado al presente y en donde es necesario pensar en actividades para que los niños aprendan disfrutando y divirtiéndose, tocando y experimentando, compartiendo con otros. Sería interesante continuar indagando acerca de ¿cómo piensan los niños que se divierten y disfrutan de las 
experiencias en museos? En general los pequeños dan importancia a los objetos y los vincularon con el pasado y la historia. Esta percepción podría plantearse como desafío para los museos y las escuelas ¿Cómo trabajar para conectar el museo como lugar del pasado, el presente y el futuro? En términos de Anderson et al (2002) es necesario ofrecer mediadores que permitan contextualizar la experiencia del museo con la vida cotidiana, social, comunitaria y personal de los niños. Además se considera oportuno ofrecer experiencias en museos de diferentes tipos como aquellos que recuperan los aspectos modernos y cercanos de las culturas. Trabajar para aumentar y abrir la educación, es decir, ofrecer experiencias educativas diversas, en contextos distintos más allá del aula, que amplíen las oportunidades de aprender de los estudiantes (Elisondo, 2015).

En relación con las experiencias previas en los museos pudimos identificar que más de la mitad de los niños consultados conocían otros museos, pero para una importante cantidad la actividad NAVE se constituyó en su primera experiencia. En general, los niños que conocían museos reconocieron aquellos ubicados a nivel local, regional y nacional, de diversas disciplinas y modalidades. Además, conocimos que la mayor parte del grupo consultado ha visitado museos en el marco de viajes u actividades escolares, así como en vacaciones y viajes con la familia. En las experiencias previas de los niños con los museos, la escuela ocupa un lugar relevante, a tal punto que al menos dos pequeños piensan que tal vez no vuelvan al museo si la escuela no los lleva. La escuela, tan cuestionada en nuestros días es capaz de comprometerse para ofrecer experiencias culturales, sociales e intelectuales que amplíen las perspectivas y horizontes de las personas.

La educación formal en todos sus niveles, incluyendo a la universidad, debe comprometerse en el diseño de propuestas que desafían a las personas, que las involucren de modo integral desde lo intelectual y lo afectivo. Desde diversos lugares escuela, familia y museos es necesario renovar el compromiso para lograr mayor inclusión social (Escarbajal y Martínez, 2012); que los niños se sientan competentes, adquieran confianza en su habilidad de aprender y explorar por sus propios medios.

Cuando los niños mencionaron los museos que conocen, la mayoría señala instituciones locales, regionales y nacionales. Es un desafío para la escuela y las familias que los chicos pueden conocer museos que se encuentran en otros países. En este sentido numerosos museos 
internacionales, poseen extensiones en el espacio virtual que permiten desarrollar excelentes oportunidades para aprender, los museos virtuales de Google presentan herramientas a la hora de diseñar experiencias que involucren museos, más allá del contexto próximo de los niños.

En cuanto a las valoraciones realizadas de una actividad particular destinada al público infantil, los niños consultados mencionaron que construyeron conocimientos, señalaron que 'aprendieron más' sobre determinados contenidos como planetas y el sistema solar, aviones y muchas otras cosas. Asimismo construyeron nuevos aprendizajes vinculados a experiencias tales como subir a aviones o conocer sobre el entrenamiento militar de perros (aspectos vinculados al patrimonio cultural inmaterial de una institución). Los niños consultados enfatizaron la idea del museo como espacio para ver y observar, tal vez esta percepción sirva para replantear algunas actividades proponiendo, un rol más activo que contemplativo para los niños; invitaciones donde puedan además de 'contemplar', crear, jugar, hacer, manipular, contar, sentir, emocionarse, entre otras. Investigaciones como las de Anderson et al (2002), Chavez Cedrón (2016) y Castro (2003) permiten conocer que en algunos casos los niños asocian los que hacen en los museos, con lo que es el museo. Trabajar en mediadores que lleguen a los niños desde los diferentes contextos personal, social y físico es un desafío si queremos sorprenderlos.

En cuanto a la satisfacción con la experiencia, la mayoría de los niños la perciben de manera positiva. En el apartado donde se consulta sobre sugerencias y modificaciones indican: Nada ¡Todo me gustó! aspecto que luego es reforzado cuando se consulta sobre los deseos de regresar al museo. Un grupo de chicos, señalaron algunas sugerencias tales como revisar actividades particulares (video Paka-Paka), e indican partes del museo que no les agradaron por razones personales.

En general todos pudieron construir significados acerca de sus experiencias, mencionaron aprendizajes percibidos y aspectos que modificarían. Se podría suponer que tal vez el museo fue percibido de manera positiva justamente porque se preparó para recibir niños, aspecto que resulta interesante en un doble sentido; como desafío para aumentar los esfuerzos en el diseño de propuestas adecuadas a cada público y como posibilidad de investigar qué sucede cuando los niños participan de actividades tradicionales como visitas guiadas. En síntesis podría indagarse si varían las percepciones en función de las actividades de las que participan. 
La principal limitación del estudio es la imposibilidad de generalizar los resultados a otros grupos de niños sin tener en cuenta los contextos. Esta limitación se podría superar a partir de la investigación en diferentes contextos y con diferentes grupos. También sería interesante, complementar el análisis con datos provenientes de otras estrategias de recolección de datos como entrevistas y observaciones. Para una futura investigación se podrían estudiar las relaciones entre diferentes dimensiones, tales como pertenencia escolar institucional y percepciones, experiencias y valoraciones de niños; comparar las percepciones de los niños en función de diferentes actividades realizadas en los museos (por ejemplo con las familias). Los resultados del estudio constituyen un corpus susceptible de ser ampliado en futuras investigaciones tanto en el campo local como internacional.

\section{Agradecimientos}

Al Consejo Nacional de Investigaciones Científica y Técnica (CONICET) de Argentina, a la Universidad Nacional de Río Cuarto, al Museo Tecnológico Aeroespacial y al Observatorio Astronómico de Córdoba.

\section{Referencias}

Anderson, D., Piscitelli, B., Weier, K., Everett, M. y Tayler, C. (2002). Children's Museum Experiences: Identifying Powerful Mediators of Learning. Curator The Museum Journal, 45(3), 213-231. Recuperado de https://eprints.qut.edu.au/19073/

Alderoqui, S. y Pedersoli, C. (2011). La educación en los museos. De los objetos a los visitantes. Buenos Aires: Editorial Paidós.

Alderoqui, S. (2008). Juventud y museos: el efecto mariposa. Museos, educación y juventud. En Cortes Solano, A. M. (Coord.) Memorias del V Encuentro Regional de América Latina y el Caribe sobre Educación y Acción Cultural en Museos CECA ICOM. Ministerio de Cultura (pp 75-84). Bogotá, Colombia. Recuperado de http:// www.museoscolombianos.gov.co/fortalecimiento/comunicaciones/publicaciones/ Documents/memoriaeducacionjuventud.pdf.

Alderoqui De Pinus, D. (2006). Museos adaptados a los niños y adoptados por los niños. En Alderoqui, S. (Comp.) Museos y Escuelas: socios para educar (pp 45-67). Buenos Aires, Argentina: Editorial Paidós.

Aguirre, C. y Vázquez, A. (2004). Consideraciones generales sobre la alfabetización científica en los museos de ciencia como espacios educativos no formales. Revista 
¡Todo me gustó! Los niños y sus percepciones de una actividad educativa en un museo María Fernanda Melgar

Electrónica de Enseñanza de las Ciencias, 3(3), 1-26. Recuperado de https://dialnet. unirioja.es/servlet/articulo?codigo $=1026030$

Badilla, E. (2007). Descentralizar el Aprendizaje: Nuevos Retos para la Educación. Revista Electrónica Actualidades Investigativas en Educación, 7 (especial), 1-27. Recuperado de http://www.redalyc.org/pdf/447/44709907.pdf.

Casalins, D y Miranda, T. (2012). El Museo del Caribe, Un Laboratorio de Diseño para la Primera Infancia. Revista Arte y Diseño, 10(2), 53-60. Recuperado de https://www. researchgate.net/publication/273902636_El_Museo_del_caribe_un_laboratorio_de_ diseno_para_la_primera_infancia

Castro, D. (2003). Protagonistas de museo: Niños, jóvenes y adultos en el desarrollo de proyectos pedagógicos y museográficos sobre el patrimonio arqueológico colombiano. Boletín del Museo del Oro, 51, 2-30. Recuperado de https://publicaciones. banrepcultural.org/index.php/bmo/article/view/4939

Chávez, K. (2015). Percepciones de los niños visitantes en torno al curso de verano 2014 del Museo Nacional de Culturas Populares, México. Tesis para obtener el grado de Licenciado en Turismo. Universidad Autónoma del Estado de México. Recuperado de http://ri.uaemex.mx/handle/20.500.11799/58766.

Domínguez, A. (2003). La museología participativa. La función de los educadores de museo. En Iglesias Gil, J. M. (Coord.). Actas de los XIII Cursos Monográficos sobre Patrimonio Histórico. (pp. 99- 118). Reinosa, España. Recuperado de https://dialnet. unirioja.es/servlet/articulo?codigo $=1026765$.

Dufresne, C. (2008). Análisis de 50 años de educación museal. Museos, educación y juventud. En Cortes Solano, A. M (Coord.) Memorias del V Encuentro Regional de América Latina y el Caribe sobre Educación y Acción Cultural en Museos CECA ICOM Ministerio de Cultura (pp. 53-59). Bogotá, Colombia. Recuperado de http:// www.museoscolombianos.gov.co/fortalecimiento/comunicaciones/publicaciones/ Documents/memoriaeducacionjuventud.pdf.

Dujovne, M. 1995. Entre musas y musarañas. Una visita al museo. Buenos Aires, Argentina: Editorial Fondo de Cultura Económica.

Escribano, A. (2015). Reseña de Manual para el desarrollo de proyectos educativos de museos. Revista Educatio Siglo XXI, 30(2), 445-466. Recuperado de https://digitum. um.es/xmlui/bitstream/10201/49463/1/Manual\%20para\%20el\%20desarrollo\%20 de\%20proyectos\%20educativos\%20de\%20museos.pdf

Elisondo, R. (2015). La creatividad como perspectiva educativa. Cinco ideas para pensar los contextos creativos de enseñanza y aprendizaje. Revista Electrónica Actualidades Investigativas en Educación, 15(3), 1-23. Recuperado de https://revistas.ucr.ac.cr/index.php/aie/article/view/20904

Elisondo, R y Melgar, M. F. (2015). Museos y la Internet. Contextos para la innovación. Revista Innovación Educativa. 15(68), 17-32. Recuperado de http://www.innovacion. ipn.mx/Revistas/Documents/Revistas-2015/I-E-68/3-IE-68.pdf

Elisondo, R., Rinaudo, M. y Donolo, D. (2011). Actividades inesperadas como oportunidades para la creatividad. Contextos creativos en la Educación Superior Argentina. Revista Innovación Educativa, 11(57), 147-156. Recuperado de https://revistas.ucr. ac.cr/index.php/aie/article/viewFile/20904/21043 
Escarbajal, A. y Martínez, S. (2012). El papel de la educación y los museos en la inclusión social. Una contribución desde la animación sociocultural. Revista Educatio Siglo XXI, 30(2), 445-466. Recuperado de http://revistas.um.es/educatio/article/view/160921

Falk, J. y Dierking, L. (2000). Learning from museums. Visitor experiences and the making of meaning. Walnut Creek, Estados Unidos. Editorial Altamira Press.

Fernández, L. (2002). Visitando un museo de arte con alumnos de Educación Infantil. Revista Arte, Individuo y Sociedad. 1, 437-440. Recuperado de http://revistas.ucm.es/ index.php/ARIS/article/viewFile/ARIS0202110437A/5898

Guisasola, J. y Morentin, M. 2007. ¿Qué papel tienen las visitas escolares a los museos de ciencia en el aprendizaje de las ciencias? Una revisión de las investigaciones. Enseñanza de las ciencias: Revista de Investigación y Experiencias Didácticas, 25 (3), 401-414. Recuperado de https://ddd.uab.cat/record/39801

Hein, G. 1998. Learning in the Museum. New York, Estados Unidos: Editorial Routledge. Hernández, Y. (2013). Lugares de memoria: entre la tensión, la participación y la reflexión. Revista Panorama, 7, 97-109. Recuperado de http://journal.poligran.edu.co/ index.php/panorama/article/view/434

Laboratorio Permanente de Público de Museos (2012). Conociendo a todos los públicos ¿Qué imágenes se asocian a los museos? Ministerio de Educación, Cultura y Deporte. Gobierno de España. Recuperado de https://sede.educacion.gob.es/publiventa/detaIle. action?cod=14315C.

Laboratorio Permanente de Público de Museos (2013). Conociendo a nuestros visitantes. La experiencia de la visita al museo. Ministerio de Educación, Cultura y Deporte. Gobierno de España. Recuperado de https://sede.educacion.gob.es/publiventa/detalle. action?cod=14548C.

Maceira, L. (2008). Los museos en la educación de personas jóvenes y adultas. Revista Interamericana de Educación de Adultos, 1(30), 47-76. Recuperado de http://www. redalyc.org/pdf/4575/457545098002.pdf.

Melgar, M. F. (2017) Estudio de percepciones asociadas a los museos. Desafíos para la creatividad. Revista Electrónica de Docencia y Creatividad, 5, 41-57.

Melgar, M. F y Elisondo. R (2017). Museos, formación profesional e innovación educativa en la universidad. Revista Contextos de Educación, 22, 30-37.

Melgar, M. F y Tuninetti, V. (2017) Museos y Vinculación Intergeneracional. Estudio de valoraciones de una propuesta educativa. Revista del Museo de Antropología, 10 (1): 87-96.

Melgar, M. F. y Donolo, D. 2011. Salir del aula... aprender de otros contextos: patrimonio natural, museos e Internet. Revista Eureka sobre Enseñanza y Divulgación de las Ciencias 8(3), 323-333. Recuperado de http://reuredc.uca.es/index.php/tavira/ article/ view/90/pdf_39

Múñoz, M. (2016). El estudio de las familias en los museos. En L. Pérez (Coord.) Estudios sobre públicos y museos. Volumen I. Públicos y museos: ¿Qué hemos aprendido? (pp. 243-279). México: Escuela Nacional de Conservación, Restauración y Museografía. Recuperado de https://www.mecd.gob.es/dam/jcr:fb51bccf-6592-49c8-8d0d0b476f30d1e5/publicos-y-museosi-leticia-perez.pdf

Pol, E. y Asensio, M. (2006). La historia interminable: una visión crítica sobre la gestión 
¡Todo me gustó! Los niños y sus percepciones de una actividad educativa en un museo María Fernanda Melgar

de audiencias infantiles en los museos. Revista mus-A de los Museos de Andalucia, 6, 11-21. Recuperado de https://dialnet.unirioja.es/servlet/articulo?codigo=1993605 Unal, F. (2012). Observation of object preferences of interest by children aged between 4 and 8 in museums: Antalya museum examples. Procedia, 51, 362-367. Recuperado de https://www.researchgate.net/publication/257716487_Observation_of_Object_ Preferences_of_Interest_by_Children_Aged_Between_4_and_8_in_Museums_Antalya_Museum_Examples. 